\title{
Relações Entre Manutenção e Engenharia de Produção: uma Reflexão
}

\section{Renato Vairo Belhot}

Professor Doutor -Depto. de Engenharia Mecânica,EESC-USP,São Carlos,S.P.

\section{Fernando Celso de Campos}

Doutorando em Engenharia Mecânica, EESC-USP,São Carlos,S.P.

Palavras chave: manutenção, planejamento da manutenção, gerência de manutenção.

Key words: maintenance, maintenance planning, maintenance management.

\section{RESUMO}

$O$ presente artigo visa discutir as relações que podem ser estabelecidas entre a gestão da manutenção e a Engenharia de Produção. Para tanto, são apresentadas algumas atividades e características inerentes à manutenção, tais como: o planejamento, a definição do fluxo de informações, a busca da qualidade e produtividade e, por fím, os desafios que sāo enfrentados e o perfil do novo profissional para essa área. Finalmente, conclui-se que o modelo avaliado nada mais é do que uma extração do campo de atividades da Engenharia de Produção.

\section{ABSTRACT}

The purpose of this paper is to discuss the relationship between maintenance management and Industrial Engineering. In this purpose some activities and characteristics concerning maintenance are presented, such as planning, flow information, quality and productivity, the challenges faced and the professional's profile necessary to this area. As a conclusion, it is stated that these characteristics and activities own to the IE domain. 


\section{Introdução}

Até recentemente a manutenção era vista como um mal necessário à organização, na medida em que alguém deveria responsabilizar-se pelo funcionamento do parque produtivo.

Nessa época, a manutenção era relegada a um segundo plano e não encontrava condições favoráveis para planejar e programar suas atividades. Quebrou, conserta. $\mathrm{O}$ "homem de manutenção", por sua vez, despreparado para a função e sem treinamento adequado, prestava serviços de baixa qualidade (TRAEGER, 1995).

Dentro deste contexto, o conjunto de atividades da manutenção só aparecia como mais um componente das despesas totais da organização.

A evolução tecnológica acrescentou complexidade à preservação da integridade dos equipamentos. Os novos desafios e pressões do mercado revolucionaram os conceitos de gestão empresarial. Novos padrões de qualidade e produtividade foram estabelecidos.

A necessidade da racionalização, combinada à complexidade tecnológica inerente aos produtos, processos e equipamentos, exige a modernização dos conceitos de manutenção, a partir do reconhecimento de suas participação no cumprimento dos objetivos empresariais. $\mathrm{O}$ custo de uma falha nos equipamentos, e suas consequiências, é muito alto.

Diante desta realidade, a manutenção deve ser encarada como uma parte ativa da organização, participando da minimização dos custos e da garantia da qualidade dos produtos e serviços oferecidas (BELHOT \& CARDOSO, 1994).

\section{O Contexto da Manutenção}

A partir do momento em que uma empresa tem um veículo ou um equipamento, passa a fazer sentido a preocupação com a administração racional desse bem.

Isso se justifica por várias razões:

a) os equipamentos e veículos são bens de produção de custo elevado;

b) os veículos são bens "que se movem", criando oportunidade para atritos, desgaste decorrente das condições ambientais, danos ao próprio veículo, a outros veículos, a pessoas como o motorista e ajudante ou terceiros;

c) os equipamentos são responsáveis pela materialização dos produtos, cuja qualidade é afetada por desgastes e falhas;

d) os veículos transportam pessoas $e$ também bens materiais de valores às vezes muito elevados, desempenhando um papel de extrema importância em diferentes sistemàs produtivos;

e) os equipamentos geram produtos e resíduos que têm conseqüências ambientais e financeiras;

f) a empresa precisa ter um retorno sobre investimentos feitos em equipamentos e veículos, para preservar seu poder de reposição e garantir sua competitividade. 
Essas e outras razões de igual peso demandam um planejamento empresarial e, por conseqüência, a gestão do sistema de manutenção. Porém, a área de manutenção ainda recebe pouca atenção por parte da maioria dos empresários e gestores de um modo geral. Um dos aspectos que reforça esta argumentação refere-se à mão-de-obra utilizada na manutenção, onde o grau de instrução das equipes de manutenção impede que sejam obtidos aproveitamentos satisfatórios durante os cursos de treinamento a que são submetidas. Não é raro que equipes de manutenção acabem se transformando, então, em trocadoras de peças sem sequer questionarem as causas das falhas ocorridas nos componentes.

Outros fatores também corroboram negativamente para essa situação, como: a discriminação, a desvalorização profissional e os baixos salários pagos, contribuindo ainda mais para o quadro de desqualificação da área de manutenção. É desejável que ocorra a definição do perfil do "homem de manutenção", em termos de sua qualificação, atitudes e atuação.

Um fator importante é planejar o que não é feito com muito rigor pela área de manutenção. Adotam-se planos preventivos recomendados pelos próprios fabricantes, ou criados a partir deles, sem uma visão crítica-administrativa maior. Estes planos quase sempre sugerem inspeções, lubrificações e substituições periódicas de determinados componentes. A vida útil dos itens dificilmente é fornecida e, quando indicada, situa-se completamente fora da realidade aplicável.
Não existe um banco de dados para a manutenção que permita pesquisas aprofundadas com relação aos intervalos de substituição de itens para as diversas situações a que os equipamentos estão sujeitos. Não se encontram sistemas de informação que formalizem os fluxos de informação, que servem de apoio aos processos decisórios em manutenção.

A seguir são feitas algumas reflexões sobre a área de atuação da manutenção e os objetivos da engenharia de produção.

\section{Planejamento da Manutenção}

Numa empresa existe a necessidade de se fazer o planejamento da manutenção, visando a adoção de políticas de manutenção apropriadas para as operações de reparo, substituição e recondicionamento dos sistemas e componentes, e que esteja em conformidade com a estratégia de controle de recursos adotada pela empresa.

A manutenção possui duas características importantes: é um processo caro e é um processo do tipo "mão-de-obra intensiva" e, ao que tudo indica, continuará a sê-lo mesmo que se lhe incorporem mais e mais avanços tecnológicos (VIEIRA, 1991).

Portanto, o plano de manutenção deve fornecer uma base racional para a formulação de um programa de manutenção preventiva e para o estabelecimento dos princípios de controle e acompanhamento da condição dos parâmetros, além de fornecer diretrizes para a manutenção corretiva. 
Guerra (1992) afirma que é importante ressaltar que o nível de eficiência da manutenção também está relacionado aos recursos colocados à disposição dos mecânicos. Fica difícil exigir serviços de boa qualidade e de alto grau de eficiência sem se dispor das ferramentas e equipamentos necessários. Geralmente, essa condição leva à obtenção de serviços de má qualidade e de maior custo na substituição de partes danificadas.

A manutenção corretiva não pode ser programada, dada a natureza probabilística da falha $e$ as incertezas que cercam a tomada de decisão correspondente. Termina-se por concluir que é essencial a formulação de diretrizes de manutenção que orientem a tomada de decisões após a ocorrência de uma falha.

Neves (1992), relatando o aspecto de manutenção de pesquisa patrocinada pela Price Waterhouse, afirma que os índices encontrados nas empresas que usam manutenção preditiva e/ou preventiva variaram de 1991 para 1992 de $12,9 \%$ para $15 \%$ respectivamente, devido a uma série de investimentos feitos. Porém, isto não parece ter sido suficiente, pois a redução da manutenção corretiva diminuiu apenas $1,8 \%$ no mesmo período. Considera-se bastante desejável uma composição de $85 \%$ de manutenção preventiva complementada por apenas $15 \%$ de corretiva.

É de vital conveniência que se avalie detalhadamente as políticas de manutenção antes até de se estudar um procedimento para determinar o plano de manutenção mais adequado. Na elaboração de um plano de manutenção devem estar presentes sete (07) condições:

a) estudar as condições reais de funcionamento dos equipamentos;

b) analisar as falhas e defeitos observados, sobretudo as falhas mais freqüentes;

c) analisar um sistema apropriado de lubrificação e padronização dos lubrificantes utilizados;

d) definir o estoque mínimo de peças de reposição para evitar perdas de produção;

e) estudar as ferramentas especiais necessárias à manutenção e ao conserto dos equipamentos;

f) estudar possiveis modificações nas instalações, produtos e ferramentas para se conseguir uma manutenção mais fácil e rápida;

g) estudar possíveis modificações de layout para se evitar perda de tempo.

O plano de manutenção deve ser constituído pela melhor combinação das políticas de manutenção, coordenando-as com o objetivo de uma melhor utilização do tempo e dos recursos disponíveis. É importante destacar que, quando os componentes são de reposição simples, há uma aproximação do ideal das ações preventivas e corretivas pelo nível de detalhe fornecido pelo fabricante, tornando a manutenção barata e determinística. Raramente isso ocorre para componentes de repósição complexa, cuja manutenção é custosa e probabilística.

Para Bloch \& Carroll (1990), uma escolha cuidadosa de prioridades em um plano de manutenção que seja 
gradativamente implementado, com vistas à manutenção preventiva, muitas vezes traz resultados economicamente mais relevantes que o emprego de técnicas de manutenção preditiva, por exemplo.

A atuação prioritária junto aos componentes "críticos" é fundamental ou ter-se-á uma manutenção muito cara. Ou seja, para defeitos ou falhas em componentes que não interrompem a operação pode-se ter uma maior flexibilidade nas intervenções sistemáticas e, por outro lado, aos que podem interromper a operação, deve-se dedicar maior atenção.

Cotti (1989) faz uma reflexão a respeito dizendo que a base da boa administração são informações confiáveis sobre os aspectos mais críticos da manutenção, isto é, sobre aqueles elementos que poderão resultar em impacto mais considerável sobre as despesas ou o rendimento.

Um plano de manutenção pode ser estabelecido adotando-se como critério: horas de funcionamento, consumo de combustível ou a quilometragem rodada. $O$ primeiro critério se aplica melhor a equipamentos estacionários; o segundo se adequa a operações do tipo "coleta de lixo" em que, mesmo com o veículo parado, há desgaste das peças do motor em funcionamento; o terceiro critério é o mais comumente usado para frota de veículos, devido à existência de odômetro.

Para que se possa comprovar a economia obtida com um plano de manutenção implantado, devem ser realizadas medidas anteriores e posteriores à sua aplicação.

\section{Sistematização do Fluxo de Informações}

Dando continuidade a idéia de garantir modernidade à manutenção, é importante que a sistematização das atividades seja estabelecida a partir de uma filosofia de manutenção, que leve em consideração os recursos materiais e humanos disponíveis.

Duffuaa et al. (1992) partem do princípio que para se avaliar o nível de qualidade de um sistema de manutenção quanto à precisão da informação circulante é imprescindível a execução de uma análise em dois estágios.

No primeiro estágio, tira-se uma "fotografia panorâmica" do sistema organizacional vigente, avaliando-se seus diversos níveis e verificando-se as implementações. No segundo estágio, passa-se em revista todos os padrões, procedimentos e a disponibilidade dos recursos de manutenção quanto a sua adequação às necessidades do sistema vigente e do sistema futuro da organização.

A verificação da eficiência do fluxo de informações em uma empresa acontece mediante a avaliação de toda a documentação de padrões e procedimentos usados para consultas, dos formulários circulantes para controles e do nível de inteligibilidade dos sistemas de códigos e classificações usados (CAMPOS, 1994). 
Os procedimentos podem ser verificados em uma empresa através da sua comunicação informal no dia-a-dia do seu modus operandi ou através de documentação escrita composta de manuais elucidativos dessas ações.

Para Cunha \& Guimarães (1993), o inconveniente dessas formas é o obstáculo à dinamização e à modernização da informação circulante, no primeiro caso devido à tendência de centralização $\mathrm{da}$ informação em um ou outro indivíduo que pode a qualquer momento deixar o quadro de efetivos da empresa, criando uma lacuna que pode custar a ser refeita e, no segundo caso, devido à não revisão periódica da documentação escrita, que pode levar a que novos funcionários cometam erros graves devido à obsolescência dos manuais.

Se assim deve ser para os procedimentos, para os formulários, que são o veículo de registro da informação circulante, deve estar assegurado o fator "nitidez e clareza" para viabilização dos controles e levantamentos necessários.

Informações devem ser coletadas e tratadas, para que após análise se tomem decisões eficazes e em tempo oportuno. Por outro lado, o tratamento das informações poderá ser feito através de sistemas manuais. ou informatizados, dependendo da complexidade e do volume de atividades. Em qualquer dos casos, porém, tudo inicia-se com um formulário claro, inteligível e completo. Ele se torna peça de fundamental importância para racionalizar as operações de planejamento e controle da manutenção.
Do ponto de vista do tratamento da informação, Linzmayer (1985) comenta que a classificação e codificação dos materiais e dos equipamentos é considerada básica para a introdução do sistema administrativo, facilitando o controle e a posterior mecanização do processo.

\section{Qualidade em Manutenção}

A cada dia, diferentes exigências de mercado exercem pressões sobre as empresas sobre a forma de convulsão dos negócios. Essas pressões são geradas pelo ambiente externo, pelo ambiente interno e pelos impactos do desenvolvimento tecnológico.

As pressões internas são originadas pela inadequação dos sistemas administrativos e da mão-de-obra utilizada. As pressões externas são geradas pelos consumidores $\mathrm{e}$ pela concorrência, por conta de novos produtos de baixo custo e alta qualidade.

Novos padrões gerenciais e de qualidade estão sendo impostos às empresas, o que acabou por valorizar as atividades de manutenção, por sua participação direta na preservação da capacidade de produção e, indiretamente por sua colaboração na obtenção da qualidade dos produtos.

Manutenção Zero Defeitos, Manutenção Produtiva Total (TPM), Qualidade dos Serviços de Manutenção, entre outros, dão novo vigor à função manutenção. 
Para se assegurar e manter a qualidade dos serviços prestados, pode-se utilizar o Programa de Garantia de Qualidade na Engenharia de Manutenção (PQuEM), que, sem usar ferramentas sofisticadas ou procedimentos rigorosos, centraliza sua atuação no elemento mais importante de todos: o homem de manutenção (NAZARENO et. al., 1993).

Mirshawka (1991) afirma que o Controle de Qualidade da Manutenção (CQM) reduz os custos ocasionados pela falta de qualidade tais como perdas por quebra de produção, materiais e mão-de-obra mal aplicados, reversão da imagem negativa externa, acidentes diversos, entre outros. É a revolução de mentalidade onde o "Qualium" vence o "Quantum".

A meta da TPM consiste na obtenção de melhor rendimento para o sistema de produção, através da participação de todos os empregados nas atividades da manutenção produtiva. De forma semelhante ao Controle de Qualidade Total (TQC), onde a atenção maior na qualidade deve estar mais voltada para o processo que para as inspeções do produto, na TPM a manutenção preventiva prevalece sobre a manutenção à demanda.

Morais (1993), comenta os efeitos de um programa de TPM aplicado em uma empresa desde a sua implantação, descreve todas as atividades executadas, e avalia os resultados finais, que são: aumento da disponibilidade dos equipamentos de 90 para 95.3\%; redução dos custos de manutenção de US\$ 285 para US\$ 92 por equipamento/mês; melhoria na higienização das áreas operacionais e aumento da satisfação dos trabalhadores envolvidos.

Consegue-se atingir metas na direção do Zero Defeito através de cuidados elementares utilizados para combater causas potenciais de falhas, quais sejam: desgastes, corrosões, trincas, barulhos, vibrações excessivas, folgas e sujeiras.

Na concepção de alguns autores, o ideal em manutenção não é reparar o equipamento e deixá-lo como era antigamente, mas sim repará-lo e deixá-lo melhor do que era quando novo, ao mínimo custo global e dentro de padrões estabelecidos de produtividade e qualidade.

Estão cada vez mais presentes na manutenção os programas de gestão da Qualidade Total, implantação e adequação às exigências das normas ISO 9000 . O "homem de manutenção" deverá estar ajustado a estas novas condições de trabalho.

\section{Os Desafios Colocados à Gestão em Manutenção}

Ao se analisar as tendências recentes da organização produtiva de países desenvolvidos, identifica-se o surgimento de uma estrutura com características distintas do que tem prevalecido até hoje. Essa nova estrutura surge em função da crescente complexidade e diversificação da tecnologia, da necessidade das empresas 
tornarem-se mais flexíveis para lidar com mercados cada vez mais dinâmicos e para atender às novas exigências colocadas pelos consumidores.

Como a busca mundial de qualidade e produtividade tem se refletido em redução de custos e aumento da competitividade das empresas, a função manutenção tem que estar preparada para executar adequadamente as suas funções de planejamento e controle.

Esses padrões de qualidade e produtividade podem ser compreendidos como tendo várias facetas que guardam relações recíprocas: um melhor planejamento da manutenção; o uso da manutenção produtiva total; a realização de programas de treinamento e capacitação adequados ao nível gerencial e operacional da mão-de-obra envolvida com as tarefas da manutenção; o estudo e a implantação de programas de redução de custos; o planejamento de compras e o dimensionamento dos estoques de componentes e sobressalentes; a aplicação de recursos de informática e de sistemas de informação; e, por fim, a busca equilibrada da terceirização.

A mudança do padrão gerencial faz-se necessária para que as empresas não percam competitividade para os seus concorrentes mais imediatos, principalmente, face ao atraso tecnológico que nosso país enfrenta em relação aos países mais desenvolvidos.

Nesse contexto surge um novo modelo quanto à forma de competição entre empresas, onde um dos aspectos relevantes é a competência para transformar necessidades de mercado em oportunidades de trabalho.

Evidentemente, as exigências do mercado de trabalho em manutenção acabarão por exigir um profissional para atuar diretamente na atividade produtiva, supervisionando o uso de tecnologias, máquinas e equipamentos, desenvolvendo métodos e processos.

O aumento da automação provocará mudanças nas funções de manutenção, que estarão mais concentradas na fase de concepção de novos sistemas de operação e gestão dos recursos.

Os profissionais para atuarem em manutenção deverão estar adequadamente preparados, pois as tecnologias emergentes serão desenvolvidas e mantidas por equipes interdisciplinares, com a responsabilidade de obter produtividade no uso dos recursos e qualidade nos serviços prestados.

Para atender a esses requisitos é necessário que esse profissional tenha sólidos conhecimentos nas áreas básicas, capacidade de gerenciar através do uso de recursos computacionais, com pleno domínio dos conceitos de qualidade e produtividade e competência para aplicá-los adequadamente. É requerido também a compreensão dos processos administrativos, econômicos e sociais presentes nas organizações e a habilidade para liderar grupos de trabalho.

A análise das atividades de manutenção foi feita a partir do modelo e da visão da 
Engenharia de Produção. Explorar estas oportunidades, é uma tarefa relativamente fácil para o engenheiro de produção, que reúne as características profissionais e pessoais necessárias para atuar em manutenção.

\section{Referências Bibliográficas}

BLOCH, H.P. \& CARROLL, J.R. Preventive maintenance can be more effective than predictive programs. Oil and Gas Journal. v. 88 , n. 31 , p. 81-86, July/1990.

BELHOT, R.V. \& CARDOSO, I.A.P. Reflexos da manutenção no contexto global da organização. Metalurgia \& Materiais, v. 50 , n. 432, p. 766-769, Agosto/1994.

CAMPOS, F.C. Um sistema de apoio à decisão em gerência de manutenção de frotas de veículos. Dissertação de Mestrado, EESC-USP, São Carlos, S.P., (113p), 1994.

COTTI, L.R.M.C. Formulários para administração racional da frota. Síntese, São Paulo, 1989.

CUNHA, C.J.C. \& GUIMARÃES,V.N. $O$ significado de racionalidade em problemas de decisão. In: Anais do XIII Encontro Nacional de Engenharia de Produção (ENEGEP), Florianópolis, v. II, p. 1025-1029, outubro/1993.
DUFFUAA, S.O.; SHUAIB, A.N.; RAOUF, A.; BUDAIR, M.O. Evaluation of maintenance systems. Journal of King Saud University, Engineering Sciences, v. 4, p. 29-43, 1992.

GUERRA, A.R.O. Gerência de manutenção de frota de ônibus - um sistema de apoio à decisão. Dissertação de Mestrado, UFRGN, Natal, RN, (288p), 1992.

LINZMAYER, E. Administração de materiais. Instituto Mauá de Tecnologia, mimeo, 1985.

MIRSHAWKA,V. Manutenção preditiva. McGraw-Hill, São Paulo, 1991.

MORAIS, V.O. TPM - manutenção produtiva total - aplicação prática na refinaria da ALUMAR. In: Anais do 8o. Congresso Brasileiro de Manutenção, São Paulo, outubro/1993.

NAZARENO, C. \& COSTA, H.R. \& BARROS, ,W.L.S. A missão qualidade. In: Anais do 8o. Congresso Brasileiro de Manutenção, São Paulo, outubro/1993. 
NEVES, A.C. Indicadores de qualidade e produtividade. Controle da Qualidade, $n$. 10, p. 10-13, set-out/1992.

TRAEGER, A. A modernização da manutenção. Controle da Qualidade, n. 33, p. 22-25, 1995.

VIEIRA, M.G. Introdução à manutenção. Publ. EESC-USP, n. 017/92, 15p., São Carlos, 1991. 